\title{
The Evolution of Modern Zombie Comedies
}

\author{
by Katie Garrett, Ball State University
}

\begin{abstract}
Zombie comedies are a subgenre of a subgenre in the horror film industry, and their prevalence in recent film and television history is unprecedented. This essay explores the beginnings of zombie comedy movies, their evolution throughout the past decade, and the implications of this genre's new relevance and its politics. Included is an examination of a more recent Netflix Original television show, Santa Clarita Diet.
\end{abstract}

\section{INTRODUCTION TO MODERN ZOMBIE COMEDIES}

Zombie comedies are a subgenre of a subgenre of apocalyptic movies. They fit into the zombie apocalypse category for the most part, and yet they also feature a wildly different tone and subject than serious zombie movies. For example, compare Shaun of the Dead (2004) and World War Z (2013). Shaun of the Dead focuses on average people in modern British life and how they deal with a newly introduced apocalypse. World War $Z$ is far more concerned with apocalypse on a global level, with settings all over the world.

The zombie genre most notably was introduced to popular culture by George Romero in 1968 with his movie Night of the Living Dead, but the genre has since transformed and had many additions. At the beginning of the genre's prominence, according to David Christopher in his article "Zombieland and the Inversion of the Subaltern Zombie," it was easily dismissed as a low form of entertainment, and through that dismissal the genre could "avoid the scrutiny of the cultural censor" (114). As such, this genre flourished in its ability to critique popular culture, consumerism, and patriarchy without being heavy-handed; these early non-blockbuster zombie movies made an art of metaphor and of tackling difficult subjects in an apocalyptic setting.

However, as time went on, a new subgenre of the zombie movie was born. Referred to by Kyle William Bishop as a "zomedy," the zombie comedy is most easily associated with the hit movies Shaun of the Dead (2004) and Zombieland (2009) (24). Even though these movies create a site from which to criticize the zombie genre, they have come down under a fire of condemnation for refusing to deal with the issues that original zombie movies examined. This subgenre makes fun of established zombie tropes but, as a whole, refuses to 
contemplate the original critique of modern society that movies like Night of the Living Dead presented. In this vein of thought, the zomedy uses humor and comedy not to inspire genuine thought or add to the zombie genre but to succeed commercially with a wider audience.

This zomedy subgenre has flourished and continues to grow today, with new works appearing even as recently as 2017 with the Netflix original show Santa Clarita Diet. This more recent addition represents a possibly optimistic outlook for the potential of zombie comedies in the future, as it shows that zombie comedies, despite the original criticism they sustained, can be a powerful vessel for making political statements. They are allowed to stand on the base of Romero's previous work with Night of the Living Dead and expand the conversation in meaningful ways.

In this paper, I will provide an overview of opinions on several zombie comedies and on the way these zomedies deal with the original subject matter of zombie movies. While I acknowledge that the zombie comedy subgenre often departs from a place that allows for a critique of society to one of mindless comedy and insensitive violence, especially in blockbuster movies like Shaun of the Dead and Zombieland, I will use the example of Santa Clarita Diet to examine the ways that zombie comedy can be used for both comedy and as a serious form of satire.

\section{DIFFERENT VIEWS ON ZOMBIE COMEDIES}

Opinions on the value of zombie comedies vary wildly. Kyle Bishop argues in his paper, "Vacationing in Zombieland: The Classical Functions of the Modern Zombie," that movies like Zombieland "cleverly [challenge] audience expectations and [offer] viewers a glimpse of how the zomedy subgenre can function as a positive social force within both the comedy and horror traditions" (25). Bishop is convinced that the zombie comedy genre is one that is welcome and inviting to modern audiences and that, in addition, its effect is one of positivity and hopefulness. Rodger Payne says in his article, "Laughing off a Zombie Apocalypse: The Value of Comedic and Satirical Narratives," that "because these popular works infuse comedy into the horror genre, they work effectively as subversive satire, reflecting a critical rather than an entrenched understanding of fear and threats" (222). He claims that the zombie comedy is successful because of its criticism of the zombie genre in general, rather than just as a comedy or a zombie movie.

Recently, zombie movies give a different treatment of zombies than older movies. One of the reasons zombie films are so acutely horrific is the fact that the sickness is not 
something that can be seen, at first. It silently occupies the body of our friends, neighbors, and family members and replaces them. In Night of the Living Dead, the horror that zombies inspire is that killing them is painful to the main characters because they still appear as human bodies. For the sake of future humanity, these dead bodies must be stopped. However, in a zombie comedy these figures become little more than "a narrative punching bag” (Kelly 86). For example, Zombieland takes particular enjoyment in the dispatching of zombies. It even features a "Zombie Kill of the Week." In zombie comedies, the zombies aren't "people" to the main characters; they are just something to be avoided and slaughtered en-masse when possible. Kelly writes that "not only is the zombie increasingly rendered as funny (a mindless fall guy for violence gags), it is positioned within narratives as a creature that is fun to kill" (85-86). Zombies aren't a sight of fear for the protagonist characters of zombie comedies; rather, they fall more under the category of "object that must be destroyed." There doesn't seem to be much rumination beyond it. As Kelly puts it, "the zombie has transformed from a device for cultural contemplation to a figure which has become a focal point for bloody fun, a newly justified target of aggression” (84).

This trend is particularly ominous when considering what zombies really are. It isn't hard to tell what inspired the sight of bodies rising from the dead. They are victims of a plague-regular humans who caught a sickness. Even within the context of the zombie comedies, zombies aren't a coherent villain, as they have no consciousness; they are merely dead human bodies. It feels like "zombies in these films seem relatively easy to slay and do not consistently pose an existential threat" (Payne 220). At what point in watching Zombieland is the audience ever concerned for the lives of the main characters? They always have an arsenal of weapons and take enjoyment in a kind of zombie hunting.

Characters in Shaun of the Dead exhibit the same joy in killing zombies. For example, Shaun has a daydream where his stepfather Phillip gets infected and becomes a zombie. Shaun happily kills him outright, annoyed about the part Phillip has been playing in his life. This was just in a daydream, but in the reality of Shaun of the Dead, Shaun and his friend Ed make a kind of game out of killing zombies in their backyard, throwing records to attempt to hurt them. In this zombie comedy, "to kill a zombified body is not to kill a 'person' or 'hurt anyone'. Instead, it is simply enjoying an activity at an amusement park" (Payne 99). What does it mean that movies that depict human bodies being decimated in ridiculous and violent ways have become so popular? Zombieland is one of the most popular zombie comedies to date, and it is one of the movies guiltiest of using gratuitous violence against zombies. It also includes some intense coded politics about race, gender, and class, which I 
will now discuss.

The only message Zombieland gives about race is evident in the complete absence of people of color in the movie. Christopher writes that not one person of color appears in this movie as either human or zombie (119). The exclusion of every race but white has to be intentional and plays into Christopher's theory that "Zombieland normalizes a number of patriarchal social constructs including capitalist consumerism, the heteronormative bourgeoisie, and whiteness" (118). In watching Zombieland critically for indicators of race, gender, and class, it is obvious that the only target consumers of the movie are white, middle class families. This movie's choices in lack of diversity are exclusionist. Its casting says that people of color aren't main characters, aren't side characters, and aren't even zombies. They don't have a role in this world.

In addition, Zombieland has some fairly strong politics about gender. The main character, Columbus, makes it clear from the beginning that his goal is to have a girl to bring home to his family. From the start, this positions all his potential female companions as a kind of trophy to have and show off. Many aspects of patriarchal structures are visible in the narrative. Another important character, Tallahassee, has a slogan that he yells as he goes to slay zombies: "Nut up or shut up" (Zombieland 00:20:02). Wichita and her sister Little Rock are underestimated at first by the male characters, using their femininity to rob Tallahassee and Columbus by surprise; this provides some hope that the movie might not be so patriarchally minded. However, by the end of the movie, the two female characters find themselves stuck motionless on an amusement park ride, reliant on the male protagonists to save them from approaching zombie hoards.

This patriarchal gender dynamic does not simply appear in Zombieland, either. Cady and Oates, authors of the article "Family Splatters," suggest that "[m]any female main characters in 21st century zombie movies embody physical strength and emotional toughness in the heat of a zombie attack, while happily coupling in domestic tranquility after the threat has passed" (322). This is particularly true of Shaun of the Dead, where Shaun's girlfriend Liz transfers seamlessly from badass zombie killer to domesticated housewife at the end of the movie. In Zombieland, Wichita loses her ability to defend herself when she teams up with Columbus and Tallahassee.

Generally, zombie comedies-up until recently-have focused on the heteronormative, white, middle class perspective while criticizing the standards of the zombie genre. They often center around familial structures and leave behind the valuable critiques on society that made the first zombie movies so popular. Is it possible that the 
zombie comedy genre should be left for dead? Or is it possible for the zombie comedy to pull out of its conservative position and into something that is genuinely critical? In the next section, I will be analyzing a new zombie comedy—Santa Clarita Diet, a Netflix Original that began in 2017-to try to determine whether it fits the trend of previous zombie comedies.

\section{MY ARGUMENT}

Unlike Zombieland and Shaun of the Dead, Santa Clarita Diet takes a different approach to the zombie comedy. For example, one of the main characters is a zombie, but it doesn't seem as though an apocalypse has occurred (yet, at least). I will be looking for instances where the show seems to follow in the steps of the previous zombie comedies and where it deviates from them.

Santa Clarita Diet is a story about a family who lives in the suburbs. The main characters are Sheila, Joel, and Abby Hammond. Sheila and Joel are married forty-something real estate agents, and Abby is their fifteen-year-old daughter. In their neighborhood, they live at the end of a cul-de-sac and are sandwiched between the family of vigilant LA Sheriff Dan, and the family of Rick, a police officer from Santa Monica. Dan and Rick have a notso-playful relationship, and the Hammonds watch as they constantly bicker about their respective organizations. These three families comprise the main characters of the series. The first episode sets the audience up for the rest of the season by showing Sheila's descent into an odd sickness that eventually kills her. Almost as soon as she is dead, she comes back to life with a few differences.

Zombie Sheila is definitely dead: her heart does not beat. However, she does eat. At the beginning, she eats raw beef, but after she has a taste of fresh humans, she can't seem to go back. In addition, it is established that she doesn't feel pain anymore, and injuries prove that she has merely black sludge crawling through her veins. However, the physical side effects of her zombie state are just the beginning.

Before being zombified, Sheila is a little timid about life. She says to herself, "Am I bold? No, I am not ... I want to be $20 \%$ bolder. No, more, $80 \%$. No, that's too much" (So Then a Bat or a Monkey" 00:01:28-00:01:30). The zombie Sheila of the rest of the season is at least $80 \%$ bolder. Joel notices immediately that "ii]t's not just a physical thing, she's acting different" ("So Then a Bat or a Monkey" 00:12:50-00:12:54). At the beginning of the episode, it is noted that Sheila is a fan of romanticism and is not incredibly sexual. Zombie Sheila is very sexually demanding and especially requires oral sex from Joel twice. In addition, she 
pursues spontaneous decisions, such as buying a Range Rover and going out drinking with her friends. It is interesting that Sheila can no longer feel pain but seems sensitive to enjoyment instead.

At the end of Episode One, Sheila gets sexually harassed by a co-worker named Gary. She repeats her lack of interest in him time after time. Eventually she pretends to give in, saying sarcastically, "Your unwillingness to take no for an answer has made me feel sexy and desirable" ("So then a Bat or a Monkey" 00:26:00-00:26:15). Sheila goes to lick Gary's fingers. Of course, she bites down instead, starting an intense gorefest full of streaming blood and death. The upbeat music in the background of Sheila's mealtime just lends to the atmosphere of vengeance. Her murder of Gary does not feel like murder; it feels like a powerful move of revenge for his harassment. That is one of the questions the show repeatedly asks its audience: is it okay to kill someone if it seems like it is justified? Sheila's main source of food throughout the show is criminals from wanted lists. Sheila and Joel get the information about her victims from their neighbor Dan, who thinks that it is Joel who is carrying out the murders. Dan tries to blackmail Sheila and Joel into killing people who are not actually criminals. Therefore, he eventually also meets a grisly end at Sheila's teeth.

The basis of the show revolves around two goals: getting a meal for Sheila and finding a possible cure for her condition. There are subplots aplenty, including Sheila's physical deterioration, Dan's blackmailing of Joel, and Abby coming to terms with the death and undeath of her mother. In addition, we see Eric, Dan's stepson, helping the Hammonds understand Sheila's condition through pop culture knowledge of zombies. Eric grows throughout the series as a character-but not as a love interest of Abby's, although they are the same age. It is refreshing to see a girl and boy just being friends and growing individually in a television show.

Undoubtedly, the set-up of Santa Clarita Diet is quite different from previous zombie comedies, as there is one glaring absence: the apocalypse. Zombieland is a complete apocalypse, with no remnant of structured civilization surviving. While Shaun of the Dead results in the world returning to a world almost identical to the one at the beginning, it also involves an apocalypse. In Santa Clarita Diet, the apocalypse is absolutely missing (though admittedly there is a potential for one if the series continues). In this story, we have zombie Sheila and another unfortunate person named Loki who Sheila tries and fails to eat, but the zombie plague hasn't spread past those two. Additionally, nobody has tried to kill Sheila yet: is it possible that the apocalypse was what necessitated brutality against zombies in the two previously discussed zombie comedies? 
At first glance, Santa Clarita Diet seems posed to be disappointingly conservative in regard to politics surrounding class, race, and gender, as the main characters are middle class and white. However, I found in my analyses that though Santa Clarita Diet's premise is not so different from those of Zombieland and Shaun of the Dead, the way it handles issues of politics is wildly different. For example, Sheila is often the center of attention in the show, and her displays of strength and power could leave Joel feeling less "manly." Nevertheless, while it is often discussed that Joel is not a fan of the murders that Sheila commits, he proves himself committed to his relationship with Sheila. He never gets angry at her for her condition, but, rather, he works to understand it. He reaches out to scientists to try to find a cure for her, but when it seems impossible for her to return to her old self, he decides that he loves her enough to accept her for who she is.

In terms of race, although people of color are not the main characters, they are not invisible. The Hammonds' neighbors are people of color. Rick is a black man, and his wife Alondra is Asian-American. In fact, most of the characters in the show beyond the Hammonds are people of color. Just like in Zombieland, there is no outright discussion of race; however in Santa Clarita Diet, people of color play important roles and are visible. Santa Clarita Diet is successful in being a funny show that deals with important issues of morality. In addition, it poses a new and interesting perspective in the zombie genre. What does it mean to have a zombie with no apocalypse? It changes the circumstance dramatically and lets us consider what it means to slaughter zombies. Eric even asks the Hammonds, "I mean, we're the real so-called zombies, aren't we? Consuming everything we want without regard for consequences?" "“So Then a Bat or a Monkey” 00:16:00-00:16:15). Santa Clarita Diet allows for some critique of society without the plot getting dragged down or becoming too serious.

\section{CONCLUSION}

It is possible for zombie comedies to successfully critique society while still being funny. In the past, even though zombie comedies criticized the unquestioned conventions of zombie movies, they also displayed their potential for presenting lazy, sexist, and racist caricatures of life. However, if zombie comedies are utilized to be genuinely critical of both zombie movies and negative societal trends, they could be powerful tools. Maybe that hasn't happened yet, but Santa Clarita Diet is a good indicator of a possible motion in this direction. Hopefully in the upcoming years the success of Santa Clarita Diet will bring positive changes to the genre of zombie comedies. 
Boluk, Stephanie, and Wylie Lenz. "Infection, Media, and Capitalism: From Early Modern Plagues to Postmodern Zombies.” Journal for Early Modern Cultural Studies, vol. 10, no. 2, 2010, pp. 126-147. doi:10.1353/jem.2011.0001.

Berger, James. After the End: Representations of Post-Apocalypse. Univ. of Minnesota Press, 1999.

Bishop, Kyle William. "Vacationing in Zombieland: The Classical Functions of the Modern Zombie Comedy." Journal of the Fantastic in the Arts, vol. 22, no. 1, 1 Jan. 2011, pp. 24-38. JSTOR, www.jstor.org/stable/10.2307/24352425ref=searchgateway:d878c659 046f9671d20f5060cd01d2e4.

Cady, Kathryn A., and Thomas Oates. "Family Splatters: Rescuing Heteronormativity from the Zombie Apocalypse." Women's Studies in Communication, vol. 39, no. 3, Feb. 2016, pp. 308-325. doi:10.1080/07491409.2016.1194935.

Christopher, David. “Zombieland and the Inversion of the Subaltern Zombie.” Horror Studies, vol. 7, no. 1, Spring 2016, pp. 111-124. doi: 10.1386/host.7.1.111_1.

Eitzen, Dirk. “The Nature of Film Comedy, or Why Is Shaun of the Dead Funny?”

Projections, vol. 6, no. 2, Jan. 2012, pp. 1-17. doi:10.3167/proj.2012.060202.

Fleischer, Ruben, director. Zombieland. Sony Pictures Home Entertainment, 2010.

Fojas, Camilla. Zombies, Migrants, and Queers: Race and Crisis Capitalism in Pop Culture. University of Illinois Press, 2017.

Fresco, Victor, creator. Santa Clarita Diet. Garfield Clove Productions and Kapital Entertainment, 2017.

“So Then a Monkey or a Bat." Santa Clarita Diet, season 1, episode 1, Netflix Original, April 8, 2018. Netflix, https://www.netflix.com/watch/80119335?trackId=13752289\&tctx $=0 \% 2 \mathrm{C} \mathrm{0 \% 2C8} \mathrm{08dfd74-2e6d-4a28-8c80-7b7af77d708a-14984115 \% 2C \% 2C}$

Kelly, Nicholas M. "Zombies Go to the Amusement Park: Entertainment, Violence, and the 21st Century Zombie in Zombieland and Left 4 Dead 2." Iowa Journal of Cultural Studies, vol. 14, Spring 2013, pp. 83-105. Digital Commons, digital.lib.uiowa.edu/ijcs/ ijcs14-08.htm. 
Wright, Edgar, director. Shaun of the Dead. Universal Pictures, 2004.

Payne, Rodger. "Laughing off a Zombie Apocalypse: The Value of Comedic and Satirical Narratives.” International Studies Perspective, vol. 18, no. 2, 1 May 2017, pp. 211-224. 